\title{
Dynamics Of Stock Market Return Volatility: Evidence From The Daily Data Of India And Japan
}

Banamber Mishra, McNeese State University, USA Matiur Rahman, McNeese State University, USA

\begin{abstract}
This paper studies the dynamics of stock market return volatility of India and Japan. The TGARCH-M model is implemented. These markets are impacted asymmetrically by bad news and good news. The return volatility persists in both countries.
\end{abstract}

Keywords: Conditional Heteroskedasticity, Volatility, Asymmetric Effects

\section{INTRODUCTION}

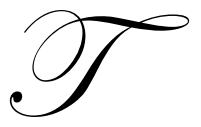

he relationship between the stock market returns and their volatilities is usually nonlinear and dynamic. This is a subject of considerable research interest. Conjecturaly, a strong positive relationship exists between stock returns and volatilities, but the strength of such a relationship varies across countries. The daily information shocks, as well as the differences in investor opinions and expectations, are the source of stock market volatility. A significant rise in stock market volatility, due to positive and negative information shocks, reduces market efficiency and liquidity. The dissemination of information is asymmetric and sequential from informed traders to uninformed traders. Consequently, an arrival of new information to the market results in price movements. The market goes through a series of sequential equilibria via portfolio adjustments before a final equilibrium is attained (Girard and Biswas, 2007).

Understanding the stock-market risk and return is important because greater volatility influences riskaverse investors to demand a higher risk premium. This, in turn, creates a higher cost of capital impeding productive corporate investment. Thus, the primary focus of this paper is to study the dynamics of the stock market volatilities of India and Japan.

India has been selected for its emerging financial and economic prominence in the world. India's Bombay stock market has been soaring as India introduced massive market deregulations and liberalizations since early 1980s. The Bombay stock market gained enormous liquidity and sophistication over the last two decades. Japan is the second largest economy in the world and its stock market as represented by the Nikkei225 is also the second largest stock market in the world exceeding \$2.6 trillion in market capitalization. High frequency daily data are employed to implement the empirics as they deem more appropriate for volatility analyses as compared to weekly and monthly data. Daily data from May 1, 1998 through September 30, 2006, as obtained from www.yahoo.com, are used in this paper.

The remainder of the paper is organized as follows. Section II briefly reviews the prior literature. Section III briefly outlines the empirical methodology. Section IV reports results. Finally, section V offers conclusions.

\section{BRIEF SURVEY OF PRIOR LITERATURE}

Numerous financial economists have employed conditional heteroskedasticity models to describe the volatility of the world's developed stock markets. The conditional volatility of stock returns in the U.S. has been examined, most notably by French et al. (1987), Nelson (1991), and Baillie and DeGennaro (1990). Masulis and Ng 
(1995), and Poon and Taylor (1992) study the volatility of the International Stock Exchange of London using GARCH. Couhray and Rad (1994) investigate the time series properties of five developed markets (U.K., France, Italy, Germany and Netherlands). More recently, Koutmous (1998) models the major stock indices of nine industrialized nations using a threshold GARCH (TGARCH) methodology.

The GARCH type models have also been employed to explain the behavior of smaller European as well as Emerging Stock Markets. Cloquette et al. (1995) model daily returns of the Belgian Stock Market for the period 1980 - 1990. Leon and Mora (1996) analyze the daily return series of the Spanish equity index, the BEX-35, for the period 1990 - 1995. Choudhry (1996) models the conditional variance of monthly returns for six emerging markets, and compares the pre-and post- October 19, 1987 periods. De Santis and Imrohoroglu (1997) model the conditional variance in nineteen emerging markets.

In the last decade, several studies of the Chinese stock markets have been conducted. Chui and Kwok (1998) report that returns of B-shares lead those of A-shares. The authors hypothesize that this relationship can be explained by the fact that information asymmetry is less pronounced for B-shares. Chakravarty et al. (1998) reached the opposite conclusion. Because foreign investors have less information than domestic investors, B shares trade at a substantial discount relative to A shares.

Fung et al. (2000) compare the Shanghai and the Shenzhen markets' response to new information. Their research indicates that Shanghai investors react more rapidly than those of Shenzhen. Xu and Fung (2002) examine the patterns of information flows for China-backed stocks that are dual-listed on exchanges in Hong Kong and New York by using a bivariate generalized autoregressive conditional heteroskedasticity (GARCH) model. They conclude that stocks listed on the domestic market play a more significant role of information transmission in the pricing process, whereas stocks listed on the offshore market play a major role in volatility spillover. Darrat and Zhong (2000) test the random-walk process of A shares in the Shanghai and Shenzhen Stock Exchanges by comparing ARIMA, GARCH, and the Artificial Neural Network models. They conclude that A-shares do not follow a random walk. Beer, Lin and Chu (2006) find evidence of asymmetric effects on Shanghai A-share and B-share indices within TGARCH $(1,1)$ model. The same apply to Shenzhen-A and Shenzhen-B shares. The volatility persistence is evidenced in all excepting Shanghai B-shares.

\section{METHODOLOGY}

In order to model the dynamics of volatility and time-varying risk premia, a natural choice would be the GARCH approach introduced by Bollerslev (1986) and Taylor (1986) as a model with an alternative and more flexible lag structure than the initial ARCH model. The model not only provides a measure of expected or ex ante volatility but also allows volatility shocks to persist over time. The main drawback of this model is that it requires constraints to be put on the coefficients to ensure non-negativity. In addition despite their popularity and apparent success in practical applications, GARCH models cannot capture the asymmetric response of volatility to news - the fact that bad news appears to induce more significant reaction than good news. Further, GARCH models do not account for the fact that investors would like to take additional risk in order to gain higher return.

To account for these limitations, Zakoian (1994) introduces the Threshold GARCH-M (TGARCH-M) model. As denoted in Beer, Lin and Chu (2006), the model contains two equations: the mean equation (eq. 1) and the conditional variance equation (eq. 2). They are as follows:

$$
\begin{aligned}
& \mathrm{Y}_{\mathrm{t}}=\mathrm{a}+\sum_{\mathrm{i}=1}^{\mathrm{n}} \mathrm{b}_{\mathrm{i}} \mathrm{Y}_{\mathrm{t}-1}+\mathrm{h}_{\mathrm{t}}^{1 / 2}+\varepsilon_{\mathrm{t}} \quad \varepsilon_{\mathrm{t}} \mid \Omega_{\mathrm{t}-1} \sim \mathrm{N}\left(\mathrm{O}, \mathrm{h}_{\mathrm{t}}\right) \\
& \mathrm{h}_{\mathrm{t}}=\sigma_{\mathrm{t}}^{2}=\varpi+\sum_{\mathrm{j}=1}^{\mathrm{p}} \alpha_{\mathrm{j}} \varepsilon^{2}{ }_{\mathrm{t}-\mathrm{j}}+\sum_{\mathrm{k}=1}^{\mathrm{q}} \beta_{\mathrm{k}} \mathrm{h}_{\mathrm{t}-\mathrm{k}}+\eta \varepsilon_{\mathrm{t}-1}^{2} \mathrm{~d}_{\mathrm{t}-1}
\end{aligned}
$$


In equations (1) and (2), $\mathrm{Y}_{\mathrm{t}}$ and $\mathrm{Y}_{\mathrm{t}-1}$ represent the returns in $\mathrm{t}$ and $\mathrm{t}-1$ respectively. The conditional standard deviation of the error term is denoted by $\mathrm{h}_{\mathrm{t}}{ }^{1 / 2}$ and the conditional variance by $\mathrm{h}_{\mathrm{t}}$ and/or $\sigma_{\mathrm{t}}{ }^{2}$. As in the majority of other publications, $\varepsilon_{\mathrm{t}}$ denotes the error term. Finally, $\mathrm{d}_{\mathrm{t}-1}$ is a dummy variable, where $\mathrm{d}_{\mathrm{t}-1}=1$ if $\varepsilon_{\mathrm{t}-1}<0$ and 0 , otherwise.

In the mean equation, the risk premium $(\gamma)$ accounts for the fact that investors might be willing to take additional risk to achieve higher returns. The conditional variance equation examines the unconditional stock price volatility through the $\beta$ coefficient. In the spirit of the GJR model of Glosten, Jagannathan and Runkle (1993), the term $\eta \varepsilon_{\mathrm{t}-1}^{2} \mathrm{~d}_{\mathrm{t}-1}$ assures that the conditional variance is positive regardless of the sign of the other coefficients. Good news $\left(\varepsilon_{\mathrm{t}}>0\right)$, and bad news $\left(\varepsilon_{\mathrm{t}}<0\right)$ impact the conditional variance ht differently. Good news has an impact of $\alpha_{\mathrm{j}}$, while bad news has an impact of $\alpha_{j}+\eta$. If $\eta>0$, the model accounts for the leverage effect.

This model captures asymmetric characteristics, such as the leverage effect, in which negative shocks have a greater effect on conditional volatility than positive shocks of the same magnitude. This also deals with volatility clustering when large (small) price changes tend to follow large (small) price changes. Additionally, it accounts for leptokurtosis and skewness which indicate departure from normality of the daily stock returns.

\section{RESULTS}

For a general understanding of the nature of each market return, some summary statistics are computed. They include mean, median, standard deviation, skewness, kurtosis, and Jarque-Bera, as reported in Table 1.

Table 1: Summary Statistics

\begin{tabular}{|l|c|c|}
\hline & $\mathbf{R}_{\mathbf{t}}$ (India) & $\mathbf{R}_{\mathbf{t}}(\mathbf{J}$ apan) \\
\hline Mean & 0.075250 & 0.025235 \\
\hline Median & 0.109699 & 0.006031 \\
\hline Std. Dev. & 1.852326 & 1.732345 \\
\hline Skewness & -0.173196 & 0.469961 \\
\hline Kurtosis & 10.65590 & 7.150701 \\
\hline Jarque-Bera & 4502.853 & 1388.569 \\
\hline Probability & 0.000000 & 0.000000 \\
\hline
\end{tabular}

The sample means are all positive. The differences between means and medians are notable. The coefficients of skewness show that India's stock market returns are slightly skewed to the left and the stock market returns of Japan are slightly skewed to the right. Excess kurtosis is observed in both cases. The Jarque-Bera test rejects the null hypothesis of normality in both return series.

Next, the time series property of each variable is examined for nonstationarity by using the augmented Dickey-Fuller (ADF) test. The ADF test results are as follows:

Table 2: ADF Tests

\begin{tabular}{|c|c|}
\hline Rates of Return & ADF-statistic \\
\hline India & -40.2651 \\
\hline Japan & -42.1808 \\
\hline
\end{tabular}

$*$ The critical values at $1 \%, 5 \%$ and $10 \%$ are $-3.4337,-2.8629$ and -2.5675 , respectively.

Table 2 shows that the null hypothesis of unit root (nonstationarity) is rejected at all the above conventional levels of significance. As both series are stationary, the question of long-run convergence in terms of cointegration does not arise.

Subsequently, the estimates of equation (1) are reported as follows: 
Table 3: Estimates of Equation (1)

\begin{tabular}{|c|c|c|}
\hline Parameters & India & Japan \\
\hline $\mathrm{a}_{0}$ & 0.1099 & -0.0003 \\
\hline $\mathrm{b}_{1}$ & $(2.1628)$ & $(-0.0049)$ \\
\hline$\gamma$ & 0.0649 & 0.0201 \\
\hline $\bar{R}^{2}$ & $(2.7523)$ & $-0.8536)$ \\
\hline $\mathrm{DW}$ & 0.0106 & $(-1.1248)$ \\
\hline $\mathrm{F}$ & $(1.3617)$ & -0.005 \\
\hline
\end{tabular}

Note: Associated t-values are reported in parentheses.

Table 3 shows that past returns influence current return in India. But this is not the case in Japan since the coefficients $\left(a_{0}\right.$ and $\left.b_{1}\right)$ are statistically insignificant in terms of the associated t-values. In other words, based on the above, the stock market of India does not follow a random walk while that of Japan does. In terms of $\gamma$, India's stock market is influenced by positive information shock while that of Japan is influenced by negative information shock.

Finally, the estimates of equation (2) are reported as follows:

Table 4: Estimates of Equation (2)

\begin{tabular}{|c|c|c|}
\hline Parameters & India & Japan \\
\hline$\varpi$ & 0.5082 & 0.5422 \\
\hline$\alpha_{i}$ & $(4.179)$ & $(5.574)$ \\
\hline$\eta$ & 0.3039 & 0.2674 \\
\hline$\beta_{i}$ & $(12.731)$ & -0.0467 \\
\hline $\bar{R}^{2}$ & 0.0562 & $(-2.379)$ \\
\hline $\mathrm{DW}$ & $(2.728)$ & 0.3211 \\
\hline $\mathrm{F}$ & 0.1475 & $(7.970)$ \\
\hline
\end{tabular}

Note: Associated t-values are reported within parentheses

Table 4 shows that all the coefficients are statistically significant. For India, $\alpha$ is higher than $\beta$ showing that prediction of volatility is dominated by ARCH-components. For Japan, the opposite inference is valid. As the $\eta$ coefficients are statistically significant, the existence of asymmetric effect is supported meaning that good news and bad news have different effects in magnitude on expected returns. The sum of the estimated coefficients of equation (2) is close to unity implying that the evolution of volatility is in a persistent fashion and that shocks may persist over a longer period of time both in India and Japan.

\section{CONCLUSIONS}

The stock markets returns data of India and Japan are non-normal and stationary. The stock market returns of India are more predictable based on the lagged-realized rates of return than those of Japan. The estimates of the mean-model show ARCH-components in the rates of stock market return in India while that is not the case for Japan. They indicate that the stock market of Japan is relatively more efficient than that of India. There are evidences of asymmetric effects of bad news and good news on stock market returns of India and Japan. Apparently, India's stock market is influenced more by positive news and Japan's stock market is influenced more by negative news. There is also evidence of volatility persistence in both markets.

These findings challenge the concept of informational efficiency. They have thus important consequences for investors and funds managers in terms of profitable arbitrages. 


\section{REFERENCES}

1. Baillie, R.T., and R.P. DeGennaro, Stock Returns and Volatility, Journal of Financial and Quantitative Analysis, 25, 203-215, 1990.

2. Beer, Fransisca M., Yu-Tsui Lin and Chi-Shun Chu, Stock Returns and Volatility: Evidence from the Chinese Markets, Journal of Emerging Markets, 11(3), 40-49, 2006.

3. Bollerslev T., Generalized Autoregressive Conditional Heteroskedasticity, Journal of Econometrics, 31, 307-327, 1986.

4. Chakravarty, S., A. Sarkar, and L. Wu, Information Asymmetry, Market Segmentation, and the Pricing of Cross-listed Shares: Theory and Evidence from Chinese A and B Shares, Federal Reserve Bank of New York, Research Paper, 9820, 1998.

5. Choudhry, T., Stock Market Volatility and the Crash of 1987: Evidence from Six Emerging Markets, Journal of International Money and Finance, 15, 969-981, 1996.

6. Chui, C. W., and C.Y. Kwok, Cross-autocorrelation between A Shares and B Shares in the Chinese Stock Market, Journal of Financial Research, xxi(3), 333-353, 1998.

7. Cloquette, J.F., M. Geard and M. Hadhri, An Empirical Analysis of Belgian Daily Returns Using GARCH Models, Cahiers Economiqeus de Bruxelles, 148(4), 513-533, 1995.

8. Darrat, A.F., and M. Zhong, On Testing the Random-walk Hypothesis: A Model-comparison Approach, The Financial Review, 35(3), 105-124, 2000.

9. De Santis, G., and S. Imrohoroglu, Stock Returns and Volatility in Emerging Financial Markets, Journal of International Money and Finance, 16(4), 561-579, 1997.

10. French, K.R., G.W. Schwert, and R.E. Stambaugh, Expected Stock Returns and Volatility, Journal of Financial Economics, 19, 3-29, 1987.

11. Fung H. G., W. Lee, and W.K. Leung, Segmentation of the A- and B-share Chinese Equity Markets, Journal of Financial Research, 23, 179-195, 2000.

12. Girard, Eric and Rita Biswas, Trading Volume and Market Volatility: Developed versus Emerging Stock Markets. Financial Review, 42(3), 429-459, 2007.

13. Glosten L.R., R. Jagannatahn and D.E. Runkle, On the Relation between the Expected Value and the Volatility of the Nominal Excess Return on Stocks, Staff Report 157, Federal Reserve Bank of Minneapolis, 1993.

14. Ho, J., The Legal Environment and Business Enterprises in the People's Republic of China, Chinese business: Challenges in the 21st century (The Chinese University Press, Hong Kong), 2000.

15. Jefferson, G.H., and T.G. Rawski, Enterprise Reform in Chinese Industry, Journal of Economic Perspectives, 8(2), 47-70, 1994.

16. Koutmos, G., Asymmetries in the Conditional Mean and the Conditional Variance: Evidence from Nine Stock Markets, Journal of Economics and Business, 50(2), 277-290, 1998.

17. Lee, G.O.M., L. Wang, L. and K. Mok, The Decline of State Owned Enterprises in China: Extent and Causes, Department of Public and Social Administration 2, 1 41. Hong Kong: City University of Hong Kong. Retrieved 03, 08-10, 1999.

18. Leon, A., and J. Mora, Modeling Conditional Heteroskedasticity: Application to Stock Return Index IBEX35, Working paper (Instituto Valenciano de Investigationes Economicas, S.A.), 3-40, 1996.

19. Masulis, R.W., and V.Ng, Overnight and Daytime Stock-return Dynamics on the London Stock Exchange: The Impacts of 'big bang' and the 1987 Stock-market Crash, Journal of Business \& Economic Statistic, 13(4), 365-378, 1995.

20. Nelson, D.B., Conditional Hetersocedastocoty in Asset Returns: A New Approach, Econometrica, 59, $347-$ 370, 1991.

21. Poon, S.H., and S.J. Taylor, Stock Returns and Volatility: An Empirical Study of the U.K. Stock Market, Journal of Banking and Finance, 16, 37-59, 1992.

22. Taylor, S., Modeling Financial Time Series. John Wiley and Sons, New York, 1986.

23. Xu X.Q., and H.G. Fung, Information Flows Across Markets: Evidence from China-backed Stocks Duallisted in Hong Kong and New York, The Financial Review, 37(4), 563-588, 2002.

24. Zakoian, J.M., Threshold Heteroskedastic Models, Journal of Economic Dynamics Control, 18, 931-955, 1994. 
NOTES 